\title{
IN VITRO COMPARATIVE SUSCEPTIBILITY TO CIPROFLOXACIN AND VANCOMYCIN IN Enterococcus faecalis STRAINS ISOLATED FROM INFECTION
}

THESIS. A. Genaro submitted this dissertation for her Masters in Tropical Diseases at Botucatu School of Medicine, São Paulo State University, UNESP, Botucatu, São Paulo, Brazil, 2002.

Advisor: Professor Carlos Alberto de Magalhães Lopes

\begin{abstract}
Enterococcus faecalis has been considered one of the major agents of nosocomial infection; its resistance to several drugs has been the concern of health authorities. The objective of this study was to determine the antimicrobial susceptibility and presence of mutant strains in Enterococcus faecalis. Seventy-four strains were obtained from hemocultures and purulent secretions of patients hospitalized at the Hospital das Clínicas da Faculdade de Medicina de Botucatu - UNESP - between 1995 and 2001. They were analyzed in vitro for their susceptibility to vancomycin and ciprofloxacin by determining the minimum inhibitory concentration (MIC), minimum bactericidal concentration (MBC), and presence of mutant strains by determining the spontaneous mutation rate to ciprofloxacin. Vancomycin showed higher efficacy, inhibiting $98.6 \%$ of Enterococcus faecalis strains (MIC $0.06-1.00 \mu \mathrm{g} / \mathrm{ml}$ ). However, bactericidal analysis showed $73 \%$ of strains with MBC equal or higher than $64 \mu / \mathrm{ml}$. Ciprofloxacin sensitivity profile was observed in MIC and MBC classes. No mutant strains were found in this study. Some strains may be resistant to vancomycin; this requires further testing.
\end{abstract}

KEY WORDS: Enterococcus faecalis, nosocomial infection, antimicrobial susceptibility, vancomycin, ciprofloxacin, minimum inhibitory concentration (MIC), minimum bactericidal concentration (MBC), mutant strains.

CORRESPONDENCE TO: Angelma Genaro - Rua Salin Kahil, 501, Apto. 41, Vila Santana, CEP:18606-760, Botucatu, São Paulo, Brasil - E-mail: angelmagenaro@hotmail.com 